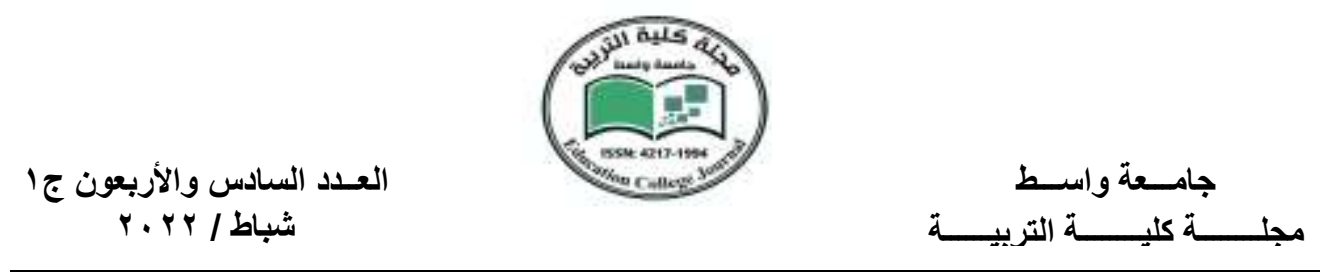

\title{
قراءة في المشكلة اللغويّة عند المحدثين
}

أ.م.د. أسعد عباس كاظم المياحي

جامعة واسط / كلية الآداب

asaadabbaas@gmail.com

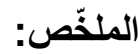

لم تسلم اللغة العربيّة منذ نزول القرآن ودخول غير العرب إلى الإسلام من الانحرافات التي

غيّرت مسارها، حتى باتت اليوم تعاني - هي وأبناؤها- من صعوبة التّحدث بصورتها اللغويّة الفصيحة، وقد كتب العديد من أبناء العربيّة مؤلفاتهم في المشكلات التي أصابت اللغة العربيّة، غير هير أننا لم نجد في ما كتبوا تحديدا دقيقاً للمشكلات فضلاً عن عدم وجود تعريف دقيق لهاء. وهذا البحث يبين - بمنهج وصفي- ماهيّة المشكلة اللغويّة ومفهومها، وأنواعها في الدراسات اللغويّة التي تتاولت هذه القضيّة، وأنواعها بحسب ما نراه نحن؛ إذ حددنا بضع مشكلات أساسية

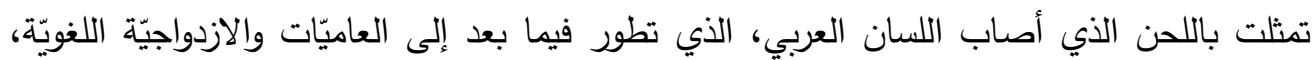
وصعوبة القواعد النحويّة والصرفيّة والبلاغيّة والكتابيّة، وضعف التدريس، وعدم تيسير تلك القواعد،

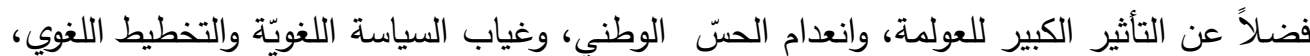
وغير ذلك.

الكلمات المفتاحية: المشكلة اللغويّة.

Dr. Asaad Abbaas Kadhim Al. Miahy

\section{A Reading of the Linguistic Problem from the Perspective of the Modernizers}

Wasit University / College of Arts

asaadabbaas@gmail.com

\section{Abstract:}

The Arabic language has not been spared since the revelation of the Qur'an and the entry of non-Arabs to Islam from the deviations that changed its course, so that today it and its children suffer from the difficulty of speaking in its eloquent language. We find in what they wrote a precise definition of the problems, as well as the lack of a precise definition of them.

This research shows the nature and concept of the linguistic problem, and its types in the linguistic studies that dealt with this issue, and its types 


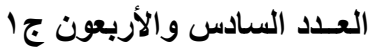

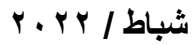

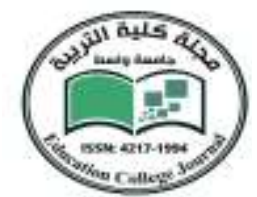

according to what we see; We identified a few basic problems represented by the melody that struck the Arabic tongue, which later developed into the vernaculars Linguistic duplication, difficulty in grammatical, morphological, rhetorical and written rules, weak teaching, and lack of facilitation of these rules, as well as the great impact of globalization, lack of patriotism, absence of language policy and language planning, and so on.

المقدّمةة:

حين دخل غير العرب إلى الإسلام بدأ اللسان العربي بالتغيّر والانحراف عن مساره، حتى باتت اليوم تعاني - هي وأبناؤها - من صعوبة التحدث بصورتها اللغويّة الفصيحة، ووجود أخطاء إملائيّة في كتابتها، وصار هذا الأمر ظاهرة واضحة للعيان تسمى بالمشكلة اللغويّة، وبدأ أبناء العربيّة يكتبون في المشكلات التي أصابت اللغة العربيّة، محاولين تشخيص تلك المشكلات وجمعها، وعلاجها ما أمكنهم ذلك، غير أنّ الملحوظ على ما كتبوا هو عدم وجود تحديد دقيقِ للمشكلات فضلا عن عدم وجود تعريف دقيق لها.

وهذا البحث يبين - بمنهج وصفي- ماهيّة المشكلة اللغويّة ومفهوهها، وأنواعها في الدراسات اللغويّة التي تتاولت هذه القضيّة، وأنواعها بحسب ما نراه نحن دون التطرّق إلى علاجها لأنّ المقام لا يسع ذلك، وقدٍ حددنا بضع مشكلات أساسية تمثلت باللحن الذي أصاب اللسان العربي، الذي تطور فيما بعد إلى العاميّات والازدواجيّة اللغويّة، وصعوبة القواعد النحويّة والصرفيّة والبلاغيّة والكتابيّة، وضعف التدري، وعدم تيسير تلك القواعد، فضلاً عن التأثير الكبير للعولمة، وانعدام الحسّ الوطني، وغياب السياسة اللغويّة والتخطيط اللغويّ، وغير ذلك.

\section{في مفهوم المشكلة اللغويّة: المشكلة:}

اختلفت الآراء في تحديد مفهوم المشكلة، فالفلاسفة يرون أنها معضلة نظرية أو علمية لا يمكن

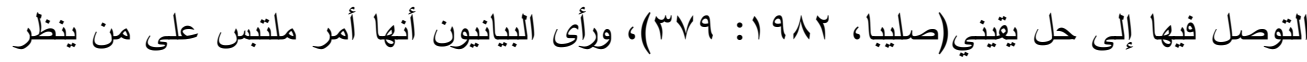

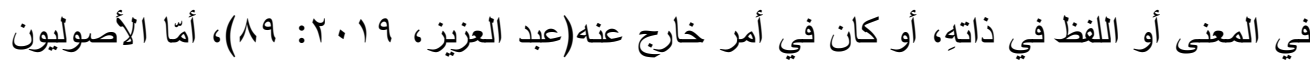
فيرون أنَّ المشكل: هو ما كانت دلالتهُ خافية عن المعنى الذي يُراد منه، إذ ينشأ من الأسلوب أو أو الصيغة، ولا يمكن إدراكهُ إلا عن طريق الاجتهاد والتأمل(الدريني، ANV I : IV)، أو ما كان معناه خافياً في نفسهِ؛ لأنَّه دخل في إثكالله، فلا يُدرك المعنى، إلا عن طريق قرينة تميّزِهُ عن غيرهِ، ويتم ذلك بواسطة التأمل والبحث بعد الطلب (أبو شنب، والعتبي، ع ( • ب: (Y). 


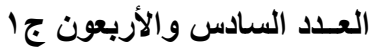

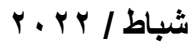

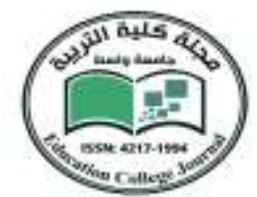

وذهب المفسّرون إلى أنَّ المشكل: هو حصول خلط والتباس بين آيتين بينهما تقارب في المعنى، إذ يكون من الصعب التوفيق بينهما من غير الإمعان في النظر (العمري، د.ت: ع)، " أو هو ما اشتبه المراد منه على وجه لا يعرف تأويلهُ إلا بدليل يتميز به عن سائر الأشكال المختلفة"

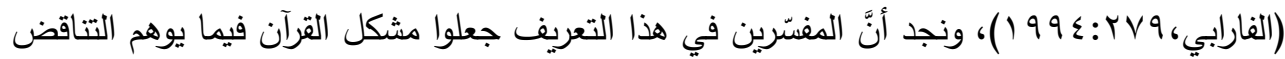
والتعارض والاختلاف، حتى أنَّ علماء علوم القرآن جعلوهُ تحت عنوان " في مشكله وموهم الاختلاف

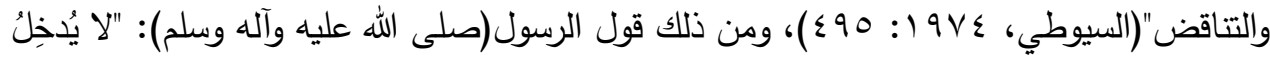

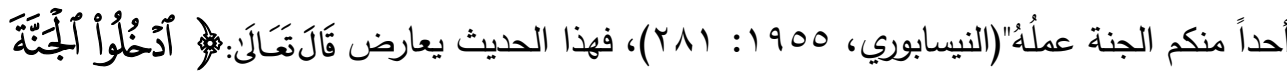

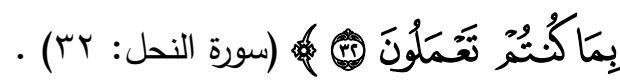

وفي المعجم اللغوي نجد أن الثين والكاف واللام أصل معظم بابه المماثلة، تقول: هذا شكلُ هذا، أي: مثله، ومن ذلك ما يقال: هذا أمر مشكل، أي: مشتبه، والإشكال: الالتباس (ابن فارس، 999 )

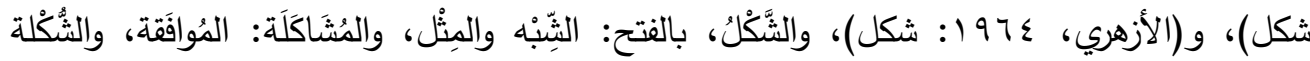

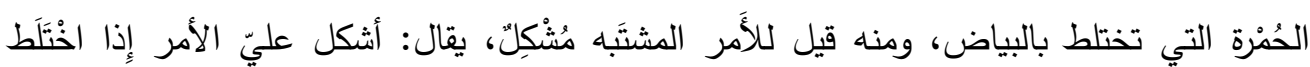

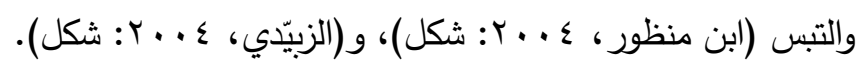
والمشكلة بين كونها معضلة أو التباساً في أمر معين، أو خفاءَ دلالةٍ أو اختلاطاً في معنى بسبب التقارب أو التماثل فإنّها موقف غير معهود، يمثل عائقاً في طريق هدف مرغوب، تجعل الفرد يشعر أمامهُ بالحيرة والتردد، مما يدفعهُ للبحث عن حل ناجع ليتخلص من هذا التردد في سبيل بلوغ الهدف؛ لأنَّ المشكلة شيء نسبي، فقد لا تكون مشكلة عند المعلم مثلما هي مشكلة عند الطالب، أمّا عند الباحث فإنَّ غايته هي العثور على الحلول المنطقية والواقعية التي يفيد منها في خدمة بحثه(أبو

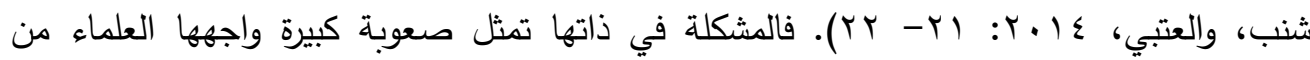
الناحيتين العلمية والعملية، وجعلته في حيرة وإربالك، وقد تطلبت جهدا عقليا وفكريا، لذلك فقد لجأوا إلى العقل الإنساني والتفكير بالحلول المنطقية والسليمة، ودراسة المشكلة من جميع جوانبها فذلك أقرب الطرق للخروج بحلول مناسبة (المياحي، إب ـ.r: 0). 


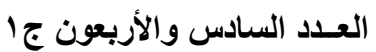

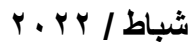

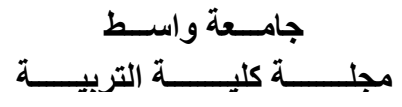

المشكلة اللغويّة:

تختلف دلالة مصطلح المشكلة من علم لآخر إذا ارتبطت بعلم من العلوم، فصطلح المشكلة

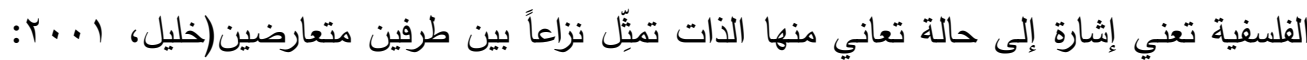
.$(1.04$

أمّا المشكلة الاجتماعية، فهي الصعوبة التي تواجه الكثير من الناس وهم يرغبون في إزالة هذه

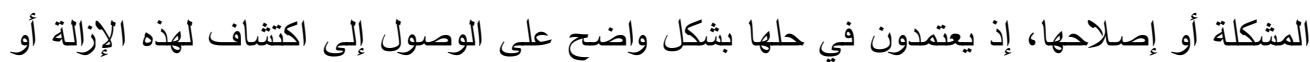

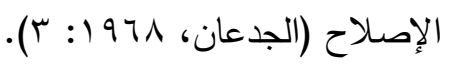

وفي القرآن الكريم فإنّ المُشكل يعني زيادة الخفاء على الخفي؛ فعندما يخفى على السامع حقيقة

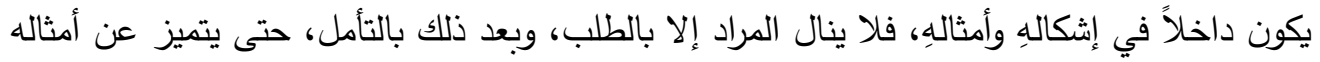

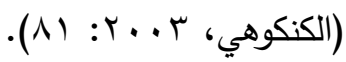

وبناءً على ما سبق، يمكننا إنَّ نعطي تعريفاً خاصاً بالمثكلة اللغويّة يتمثل بأنّها: كل ما ألمَّ

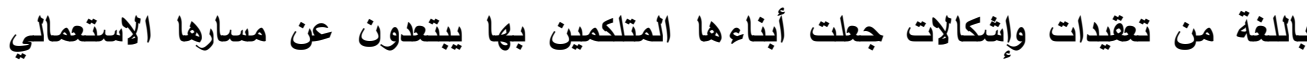
الصحيح الفصيح، بل ويعانون من الصعوبات والأخطاء حين استعمالهم إياها من ناحية القواعداء

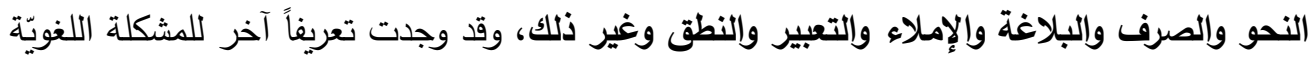

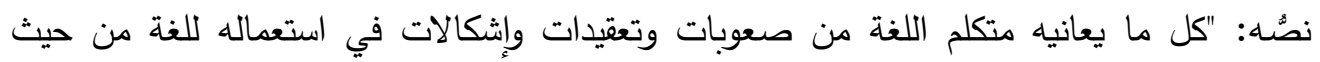

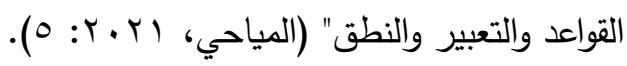

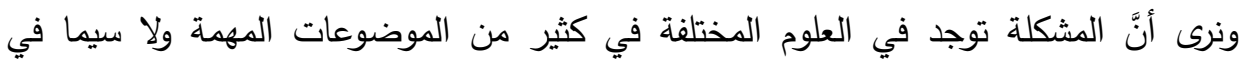

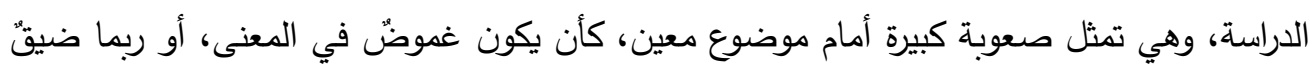

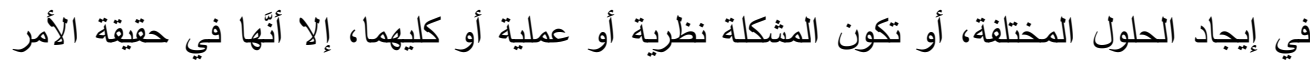

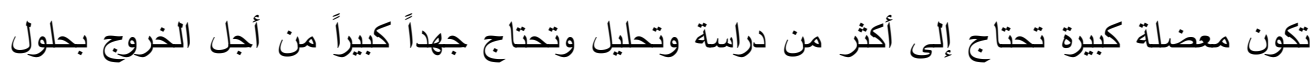

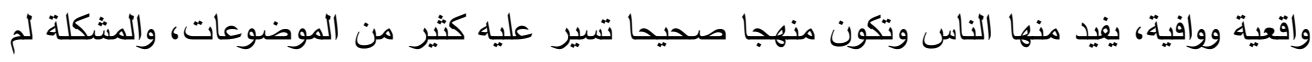

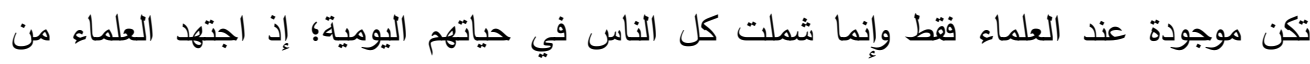
اللغويين والفلاسفة في الوصول الى حلول للمشكلات، إلا أنَّا لم توفر لهم الحلول النهائية للخروج من التهاء

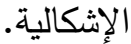




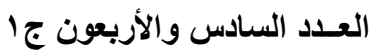

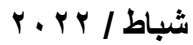

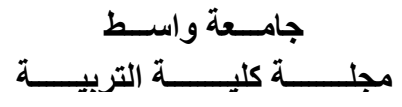

المشكلة اللغويّة في الدراسات اللغويّة العربيّة الحديثة:

لم تكن المشكلة اللغويّة في كثير من الدراسات التي تناولتها محددة المعالم، بل كانت متثعبة

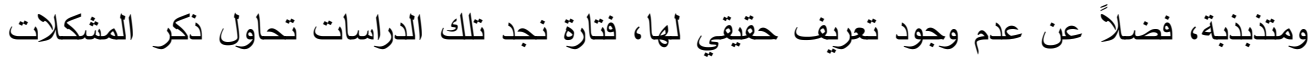

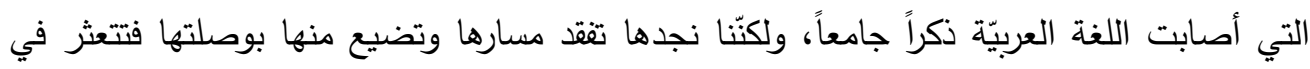

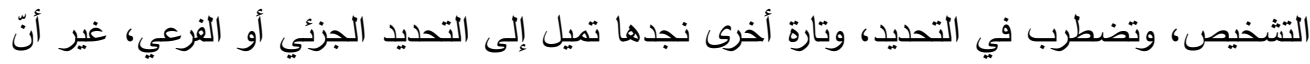

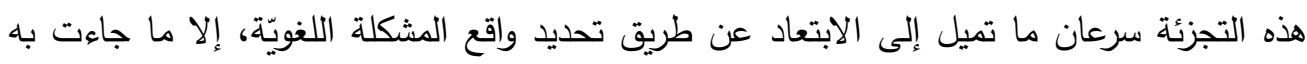

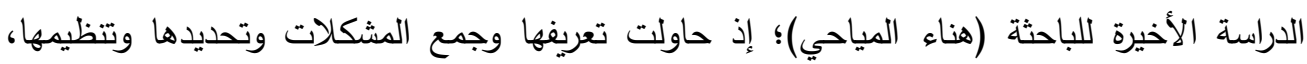
وبيان آثارها، وسبل علاجاتها.

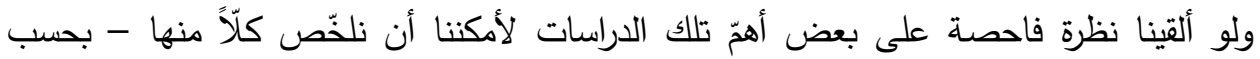

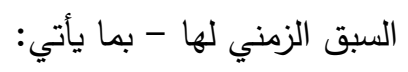
1- مشكلات اللغة العربيّة، (د.محمود تيمور):

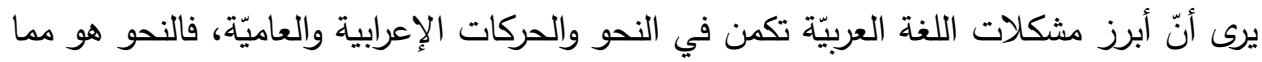
لا يمكن التخلي عنه لأهميته في حفظ قواعد اللغة، وعلامات التثكيل فيها شيء من الإنشكال؛ إذ لم الم

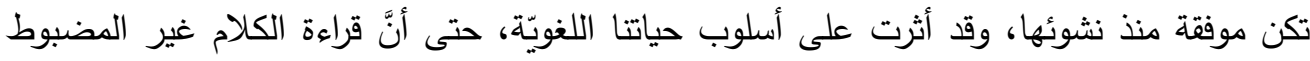

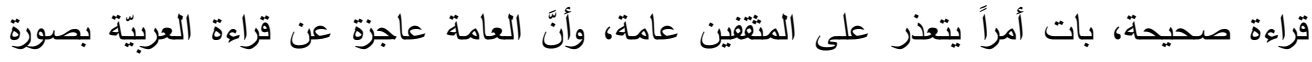

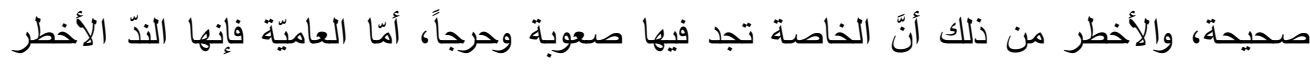
للفصحى؛ إذ إنّها أصبحت لغة الحديث اليومي عند عامة العرب، فابتعدوا عن لغتهم الأم حتى صار إنى

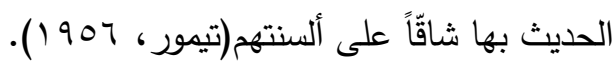

ץ - في اللغة العربيّة وبعض مشكلاتها، (د. أنيس فريحه):

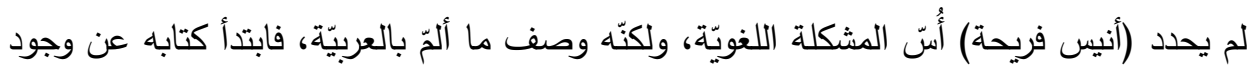

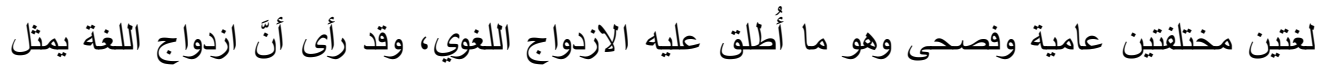

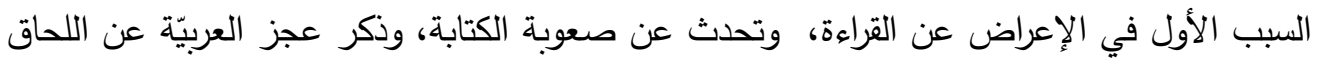

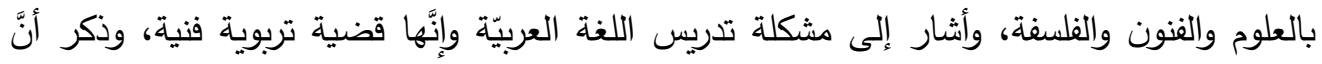

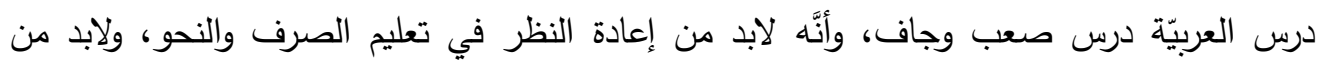

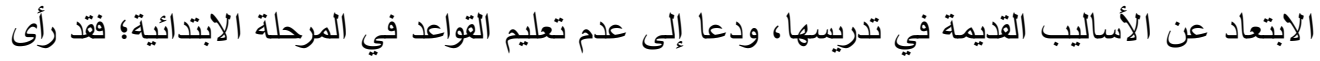

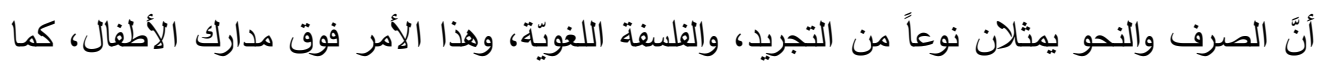
أنَّ مصطلحاتها صعبة عليهم (فريحة، .91 (1)). 


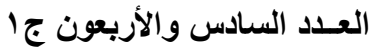

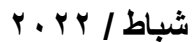

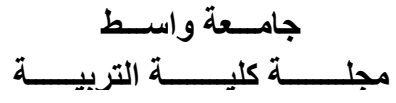

ب- مشكلات حياتنا اللغويّة، (الأستاذ أمين الخولي):

كان (الأستاذ أمين الخولي) يرى أنَّ إحدى المشكلات اللغويّة تتمثل بجمود اللغة التي تكون منافية لمطالب الحياة الجديدة، فالأزمة اللسانية لم تكن إلا أزمة اجتماعية عملية، فضلاً عمًا تعرضت الهات

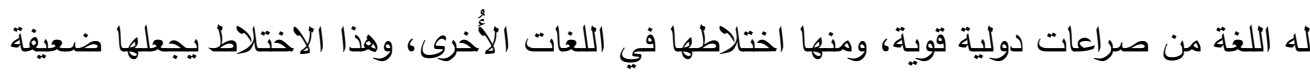

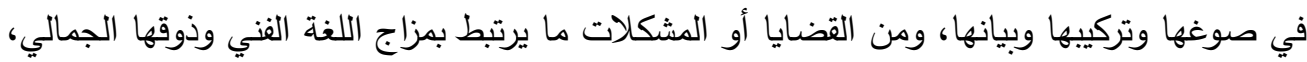

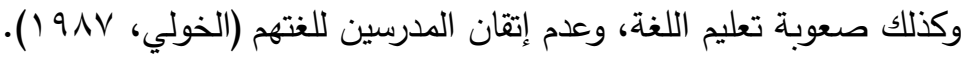
ع - مشكلات اللغة العربيّة المعاصرة، (مجد محمد الباكير البرازي):

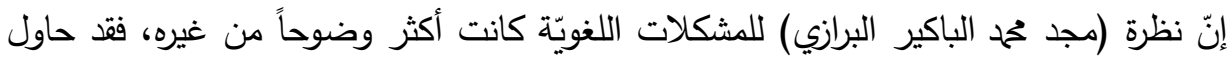

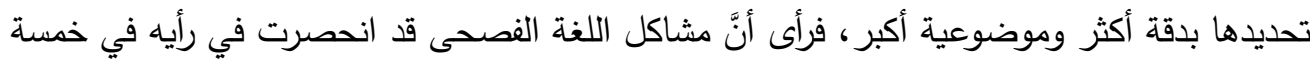

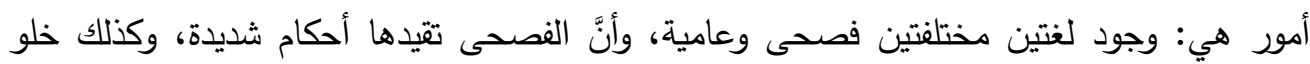

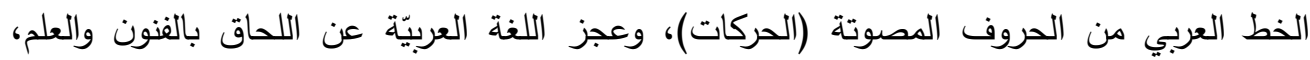
وتحجر العربيّة وعدم تطورها، فهي محصورة بين مدرستي البصرة والكوفة، وذكر (البرازي) أنّ من ون وندان

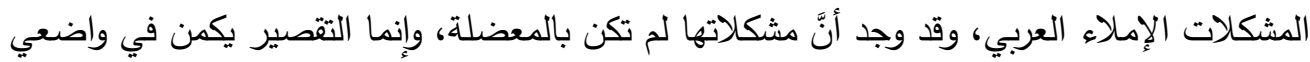
المناهج، وفي المدرسين، وفي أساليب وطرق التدريس، وأورد أمثلة عن مشكلات الهمزة، والتاء التهاء

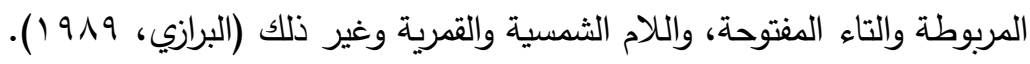

\section{ه- مشكلات اللغة العربيّة بين الوهم وسوه الفهم، (د.كمال بشر):}

حدد مشكلة اللغة العربيّة باضطراب اللغة القومية من الناحية الفكرية والعلمية والثقافية والاجتماعية، ومدى سيطرة اللهجات العاميّة على الجو العام، وانصراف الناس عن لغتهم الفصيحة،

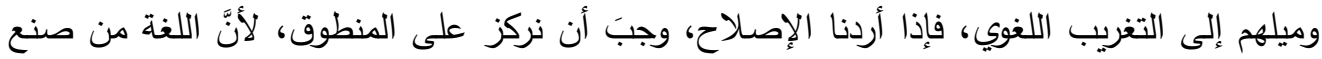

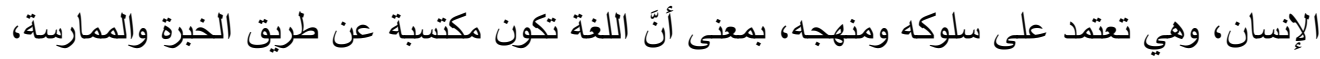

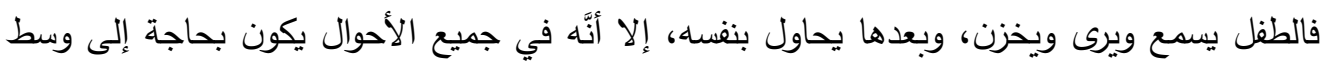
لغوي يأخذ منه. وحاول (د. بشر) تقديم منهج لقواعد اللغة يأخذ في الحسّ بان جميع ضوابط المستويات اللغويّة،

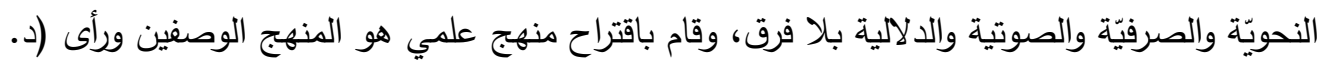

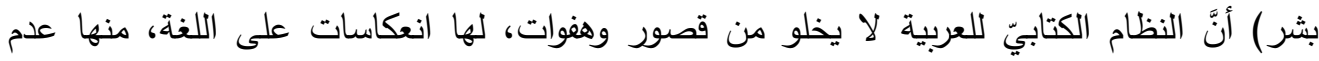

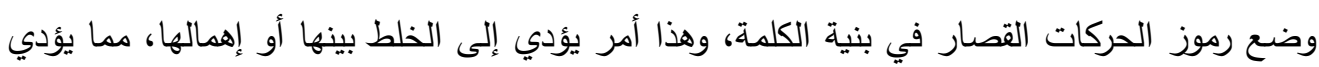

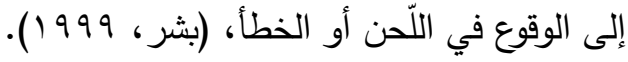




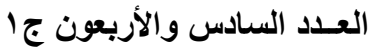

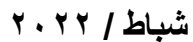

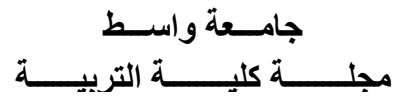

צ- قضايا اللغة العربيّة في العصر الحديث، (د. سمر روحي الفيصل):

شخّص (د. الفيصل) مشكلتان حلتا باللغة العربيّة، وكانت قضية الازدواجيّة اللغويّة أولى في لإني

القضايا التي تتاولها في كتابه، وتكلم فيها عن بدايات اللغة الفصحى والعاميّة، وحماسة الباحثين لهذا لهانها

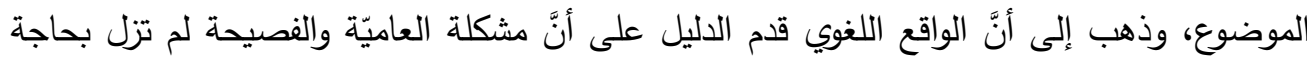

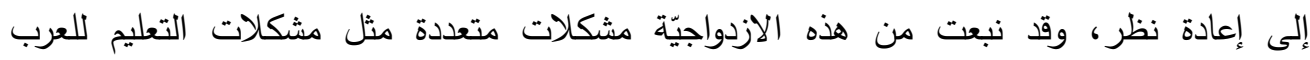

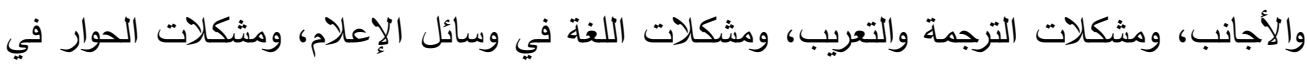

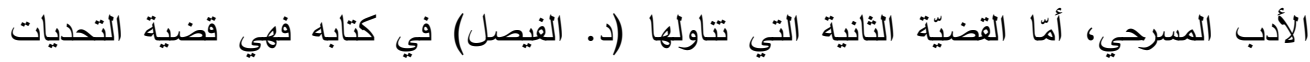

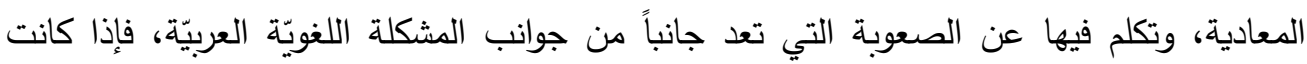

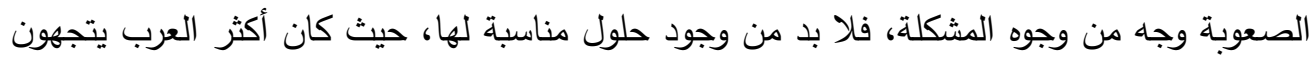

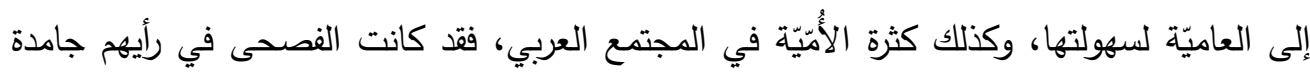

$$
\text { والعاميّة متطوّرة (الفيصل، } 9 \text {. . Y). }
$$

- V

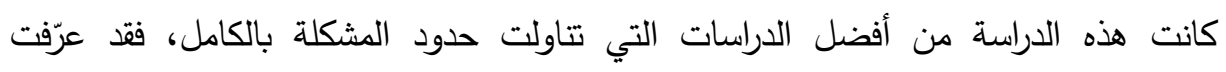
المشكلة تعريفاً لغوياً واصطلاحياً جيداً؛ ثم حددت المشكلات التي أصابت اللغة العربيّة، فتناول

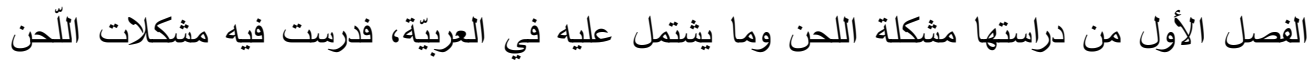

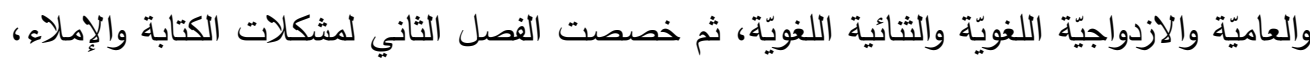

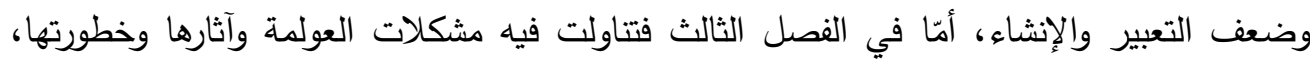

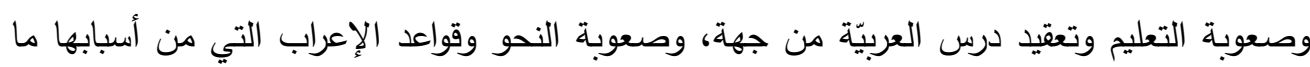

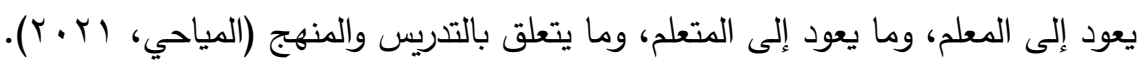
والحق: إن هذه الدراسة هي من أفضل الدراسات التي حددت مشكلات اللغة العربيّة، وكذلك بينت أساليب علاجها، وهو مما لم أجده في غيرها من الدراسات. ويمكن أن نذكر المشكلات اللغويّة التي تعاني منها العربيّة الفصحى، ونهات ويعاني منها أبناء العربيّة

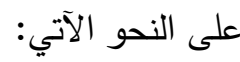
1. اللحن الذي أصاب اللسان العربي منذ دخول غير العرب إلى الإسلام، والذي تطور فيما بعد إلى العاميّات والازدواجيّة اللغويّة. r. كثرة القواعد النحويّة والصرفيّة والبلاغيّة والكتابيّة، وتداخلها، وتشعِب دلالاتها، فضلاً عن صعوبتها وتعقيدها. 
r. r. عدم إيجاد طرائق ميسرة لتدريس تلك القواعد وتحبيبها في نفوس الدارسين.

؛. انعدام الحسّ الوطني، وفقدان الهويّة اللغويّة، وضعف الدافع التحفيزي عند أبناء العربيّة لحبّها

وتعلمها وضبطها.

ه. ض. ضعف التدريس، من ناحية المعلم والمتعلم والمناهج الدراسية.

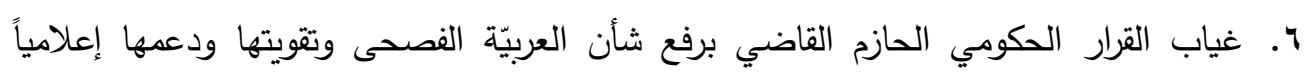

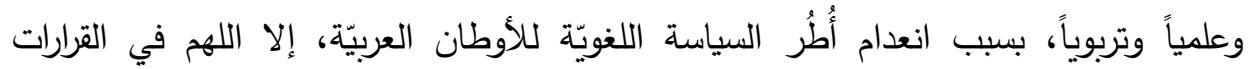
والبرامج المهمة في سلطنة عمان والأمارات.

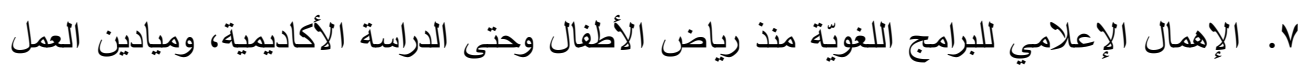

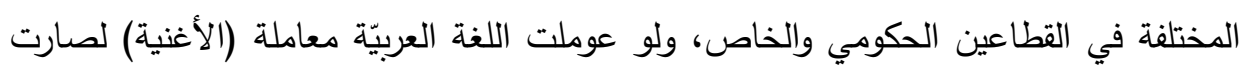
في مستويات عليا. ^. تأثير العولمة الكبير على أبناء العربيّة، واهتمام المجتمع العربي بالتغريب بدعوى التحضر والتطور .

وبدهي أنّ تتبثق مشكلات فرعيّة أخرى ترتبط بكلِّ مشكلة من المشكلات المذكورة آنفاً، وتكون

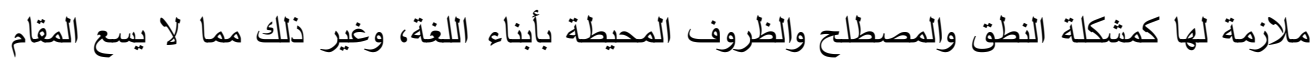

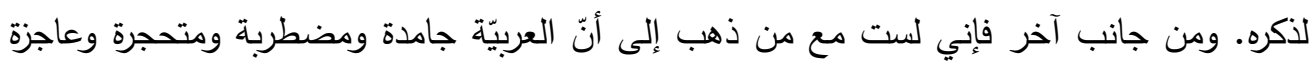

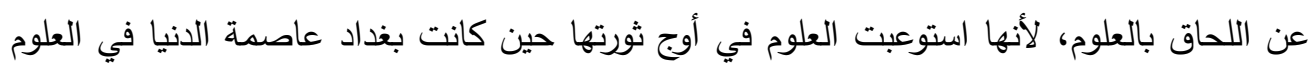

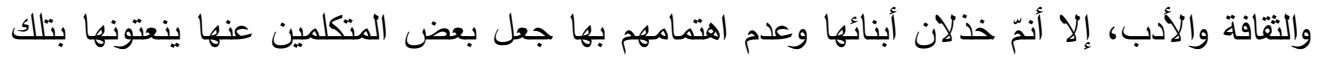
النعوت الواهنة المجحفة. ولا أرى أنّ إعادة شأن العربيّة الفصحى أمر معقد وصعب، ولكنّه يحتاج إلى سياسة حكومية محبة

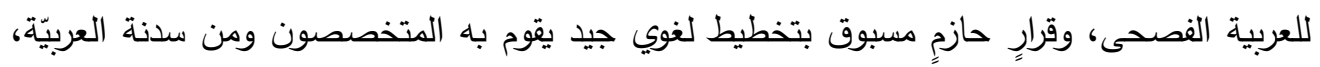

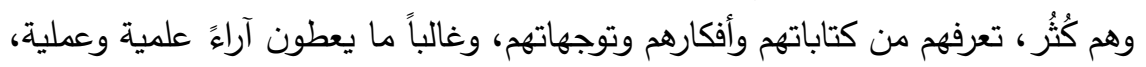




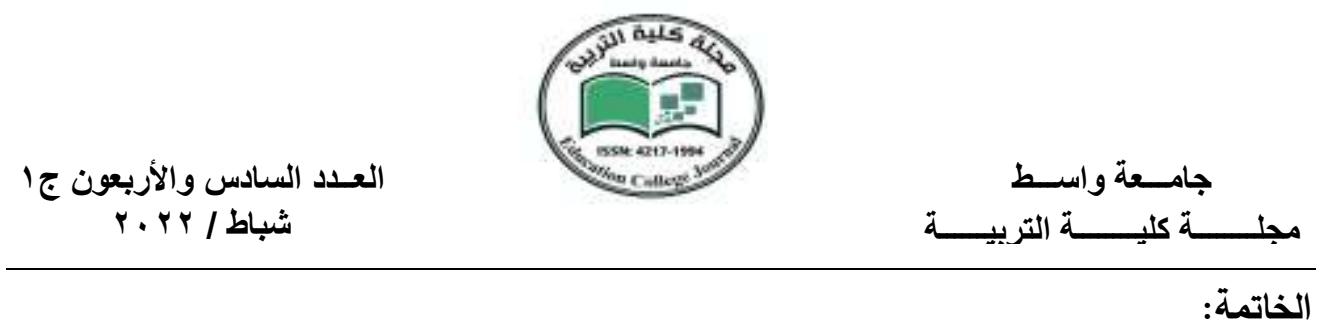

حينما انحرفت اللغة العربيّة عن مسارها الفصيح بات أبناؤها يعانون من ذلك الانحراف، وقد تتبّه العرب إلى المشكلات التي أصابت اللغة العربيّة، فألفوا فيها كتباً عدّة، بغية علاجها وإعادتها إلى لى دئى مسارها الصحيح. غير أننا لم نجد في ما كتبوا تحديداً دقيقاً لمفهوم المشكلات، فضلاً عن عدم تحديد لأنواعها وعددها. وقد بيّن هذا البحث - بمنهج وصفي - ماهيّة المشكلة اللغويّة ومفهوما، وأنواعها في الدراسات اللغويّة التي تتاولت هذه القضيّة، وأنواعها بحسب ما نراه نحن؛ إذ حددنا بضع مشكلات أساسية تمثلت باللحن الذي أصاب اللسان العربي، والذي تطور فيما بعد إلى العاميّات والازدواجيّة اللغويّة، وصعوبة القواعد النحويّة والصرفيّة والبلاغيّة والكتابيّة، وضعف التدريس، وعدم تيسير تلك القواعد،

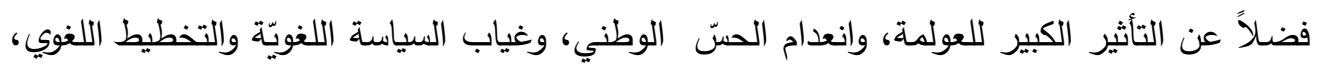
وغير ذلك. وآخر دعوانا إن الحمد الله رب العالمين، وصلى الله تعالى على سيدنا محمّد وعلى آله الطاهرين، وصحبه المنتجبين.

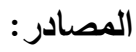
1- ابن فارس، أبو الحسّ ين أحمد (ت 90ب هـ)، الـ 1991: معجم مقاييس اللغة، ، تحقيق: عبد السلام محم هارون،

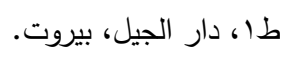

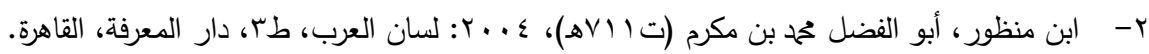

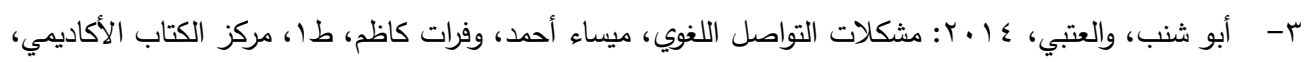
عمان، الأردن.

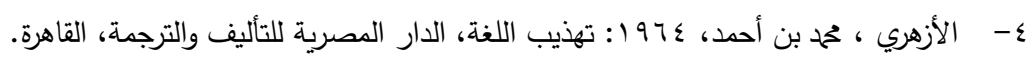

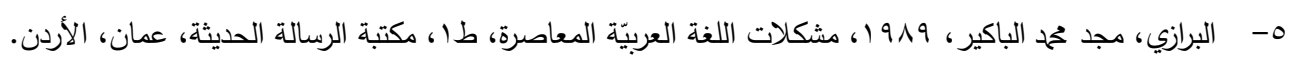

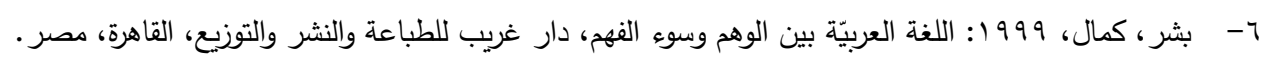

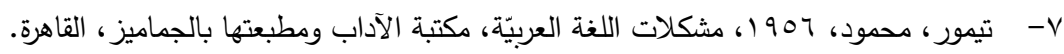
^- الجدعان، خلوف محم،

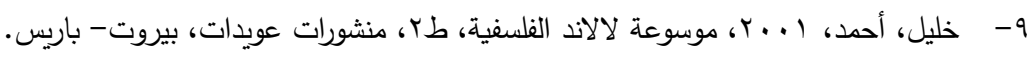

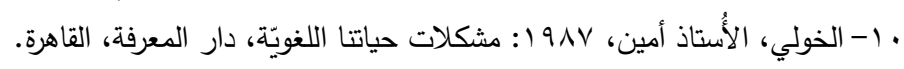

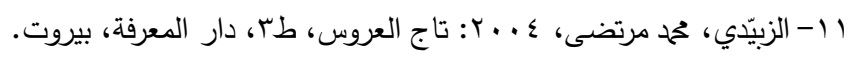




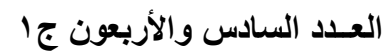

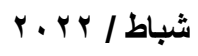

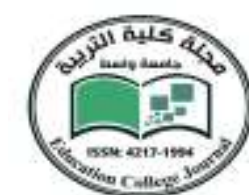

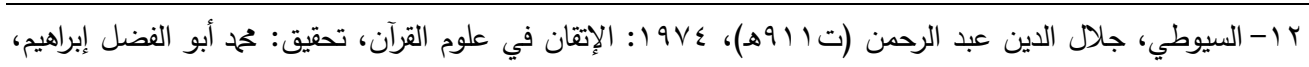
الناشر: الهيئة المصرية العامة للكتاب.

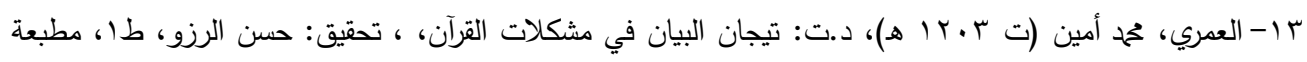

$$
\text { اشبيلية، بغداد. }
$$

ـ ا- الفارابي، عبد اللطيف، وآخرون، ـ99 19: معجم علوم التربية والديداكتيك، طا، سلسلة علوم التربية، دار الخطابي

$$
\text { للطباعة والنشر . }
$$

10- فريحة، أنيس، •1911، في اللغة العربيّة وبعض مشكلاتها، طا، دار النهار للنشر ، بيروت.

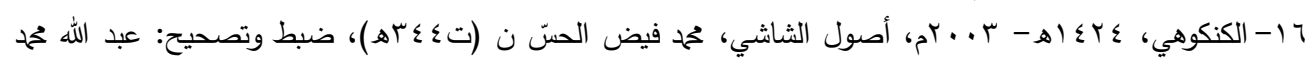

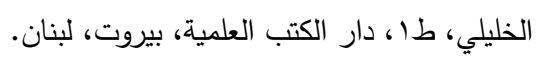

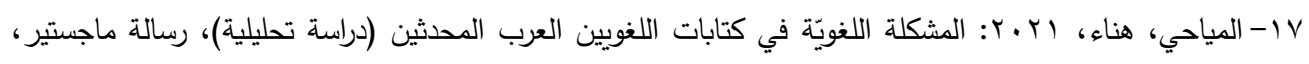

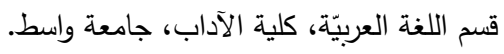

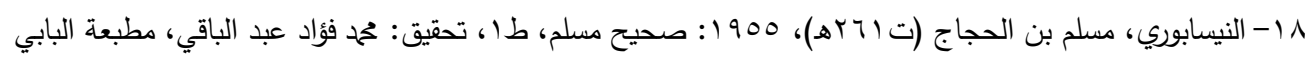
الحلبي بمصر . 